\title{
The influence of additives in modulating drug delivery and degradation of PLGA thin films
}

\author{
Charlotte L Huang ${ }^{1}$, Terry WJ Steele ${ }^{1}$, Effendi Widjaja ${ }^{2}$, Freddy YC Boey ${ }^{1}$, Subbu S Venkatraman ${ }^{1}$ \\ and Joachim SC Loo ${ }^{1}$
}

Poly $\left({ }_{\mathrm{D}, \mathrm{L}}\right.$-lactic-co-glycolic acid) (PLGA) is the most frequently used bioresorbable polymer for the controlled release of drugs. Hydrophilic additives such as poly(ethylene glycol) (PEG) are commonly incorporated into PLGA to enhance the release of hydrophobic drugs such as paclitaxel (PCTX). Understanding the factors and mechanisms that govern drug release in a blended system is important to be able to modify the delivery properties of the drugs. This study evaluated the mechanical properties of PCTX-eluting PLGA thin films that incorporate PEG additives under constant hydration, which mimics physiological conditions. The presence of additives resulted in varying extents of phase separation, which changed the degradation and release profiles of the PLGA films. The incorporation of long-chain additives resulted in large phase-separated additive-rich domains that gave rise to large pores, high mass loss, and a high burst release of PCTX from the extensive dissolution and leaching of additives upon hydration. Subsequently, the degradation rate of PLGA films was reduced by the out-diffusion of acidic byproducts through these water-filled pores and channels; these byproducts would otherwise accumulate and contribute to higher degradation rates due to the autocatalysis of PLGA. The preferential association between PCTX and PEG additives in the phase-separated PLGA films was exploited to enhance the release of hydrophobic PCTX, and statistical correlations were established between the simultaneous release of PCTX and additives. This significant correlation could provide useful information for the prediction of hydrophobic drug release profiles and the selection or preparation of localized drug delivery systems with the use of PEG additives.

NPG Asia Materials (2013) 5, e54; doi:10.1038/am.2013.26; published online 12 July 2013

Keywords: additive leaching; bioresorbable polymers; controlled delivery; in vitro mechanical properties; paclitaxel; PEG

\section{INTRODUCTION}

Controlled drug delivery is an important potential application of bioresorbable polymers because of their versatility. Pharmaceutical ingredients such as antibiotics, vaccines and anti-cancer drugs can be delivered with sustained and controlled release profiles by using timely biodegradation of the drug carrier. Biodegradable polymers such as Poly $\left(_{\mathrm{D}, \mathrm{L}}\right.$-lactic-co-glycolic acid) (PLGA) are commonly used as drug delivery carriers owing to many favorable characteristics such as biodegradability, good biocompatibility and favorable mechanical properties. $^{1-4}$ In recent decades, PLGA has been widely studied for localized drug delivery in treating periodontal diseases, ${ }^{5,6}$ glaucoma ${ }^{7,8}$ and cancer ${ }^{9,10}$ and to coat metallic stents ${ }^{11,12}$ and fully biodegradable stents. ${ }^{13,14}$

Various polymeric drug delivery systems have been investigated to optimize physicochemical properties, hydrolysis rates and drug release profiles to accommodate diverse biomedical treatments. For example, the frequency of injections in a certain therapy might be reduced by using carriers that control the release of drugs over a required period of time. Such systems are practical for patients who require long-term treatments on a regular basis. Unlike systemic drug delivery, localized drug therapy releases the drug directly at the site of disease, which leads to reduced drug wastage. The controlled and sustained delivery of the drug ensures adequate concentration over a prolonged period and thereby achieves therapeutic efficacy. This factor is especially important in cancer therapy where long-term drug-releasing implants may help prevent local recurrence events. ${ }^{15,16}$

Bioresorbable polyesters, such as PLGA, have been extensively evaluated in the past for controlled and sustained delivery in many therapeutic modalities. ${ }^{1,17-20}$ There are four possible ways in which drug molecules can be released from polymer-based drug delivery systems: (1) erosion of the polymer, (2) diffusion through the polymer matrix, (3) diffusion through pores or channels that are filled with the surrounding medium and (4) osmotic pumping. ${ }^{21}$ Owing to the typical slow release of therapeutics from PLGA

${ }^{1}$ Division of Materials Technology, School of Materials Science and Engineering, Nanyang Technological University, Singapore, Singapore and ${ }^{2}$ Department of Process Science and Modeling, Institute of Chemical and Engineering Sciences, Agency for Science, Technology and Research (A*STAR), Singapore, Singapore

Correspondence: Professor JSC Loo, Division of Materials Technology, School of Materials Science and Engineering, Nanyang Technological University, N4.1-01-30, 50 Nanyang Avenue, Singapore 639798, Singapore.

E-mail: joachimloo@ntu.edu.sg

Received 17 February 2013; revised 25 April 2013; accepted 30 April 2013 
polymers, many studies have incorporated additives such as chitosan and poly(ethylene glycol) (PEG) to enhance the kinetics of drug release. ${ }^{5,22-25}$ A variety of other techniques to enhance the release of hydrophobic drug molecules inform PLGA formulations have also been widely reported. The release kinetics of hydrophobic paclitaxel (PCTX) was improved by increasing the surface area of PLGA nanoparticles and microparticles. ${ }^{26}$ Enhanced drug release has also been reported due to increased drug loading, the use of porous matrices, and the use of excipients such as hydrophilic polymers. ${ }^{27-30}$

Excipients are either synthetic or naturally occurring, and they are incorporated into polymers through processing, chemical conjugation or blending. Natural additives such as chitosans and cyclodextrins are commonly used in PLGA-based drug delivery systems because they are biodegradable and offer excellent biocompatibility. ${ }^{31}$ However, these formulations tend to have batch-tobatch inconsistencies as a result of difficult purification processes. By contrast, synthetic polymers are available with high reproducibility and easily adjustable properties. ${ }^{31,32}$ The delivery of hydrophobic drugs such as sirolimus or PCTX from slow degrading carrier polymeric systems is commonly enhanced by the favorable incorporation of hydrophilic additives such as PEG. ${ }^{13,33-38}$ Processing, copolymerization, conjugation, adsorption and blending of PLGA with additives provide the means to exploit its favorable properties and to enhance drug delivery from PLGAbased drug delivery systems. ${ }^{2,24,39-42}$

Regardless of the drug delivery approach, detailed evaluation and characterization of these carrier systems are often neglected. Understanding and correlating the mechanisms of drug and additive releases are also important and by far rarely addressed in the literature. Here, PLGA-based PCTX-eluting thin films incorporating PEG additives at various concentrations were evaluated in detail. As with biodegradation, the mechanical properties and characteristics of the thin film change with time. These dynamic changes of the PLGA films could directly influence the release of drugs. ${ }^{14,43-45}$ Although the characteristics of polymeric films change in an aqueous environment, many studies have shown to only subjected their substrates to mere pre-wetting or pre-conditioning in an aqueous environment over several hours to days before tensile testing. ${ }^{46-51}$ This methodology does not give a true reflection of the mechanical integrity and performance of the device under physiological conditions. Here, the mechanical characteristics of PCTX-eluting PLGA thin films that include different amounts of PEG additives are characterized under constant aqueous hydration via a circulating chamber maintained at $37^{\circ} \mathrm{C}$ to mimic physiological conditions as closely as possible. In addition, the mechanical properties of these films were re-evaluated to assess the integrity of the film after a given period of degradation. Such a method of mechanical assessment has rarely been reported in the literature.

\section{MATERIALS AND METHODS}

\section{Materials}

Poly $\left({ }_{D, L}\right.$-lactide-co-glycolide) 53/47 (ester-terminated PLGA) with an intrinsic viscosity of $1.03 \mathrm{dl} \mathrm{g}^{-1}$ was purchased from Purac (Gorinchem, The Netherlands). PCTX was purchased from Yunnan Hande Bio-Tech, Kunming, China. High performance liquid chromatography (HPLC)-grade dichloromethane and acetonitrile were purchased from Tedia, Fairfield, OH, USA. Deuterated chloroform $\left(\mathrm{CDCl}_{3}+0.03 \% \mathrm{v} / \mathrm{v}\right.$ tetramethysilane D99.8\%), polysorbate 80 (Tween 80 ) and PEG with molecular weights (MW) of 400 and $10000 \mathrm{~g} \mathrm{~mol}^{-1}$ (denoted as PEG400 and PEG10k) were purchased from Sigma-Aldrich (Singapore, Singapore). All other polar solvents used were of HPLC grade and were purchased from Sigma-Aldrich. All chemicals and materials were used as received.

\section{Methods}

Film preparation. The polymer solutions at $10 \% \mathrm{w} / \mathrm{v}$ were prepared with $10 \%$ w/w PCTX in dichloromethane. PEG additives were incorporated by blending in a common solvent with PLGA and PCTX at concentrations of 10-30\% by weight with respect to PLGA. The film applicator height was fixed at $500 \mu \mathrm{m}$, and the viscous polymer blend was cast onto polyethylene terephthalate sheets at $50 \mathrm{~mm} \mathrm{~s}^{-1}$ under room temperature and pressure in a fume hood. The use of a polyethylene terephthalate layer serves to provide ease of handling of the PLGA film throughout its degradation period. The films were left to dry in an environment saturated with dichloromethane at room temperature for at least $24 \mathrm{~h}$ before being transferred to a vacuum oven for further drying at room temperature for at least one week.

Raman mapping and band-target entropy minimization algorithm. Raman microscopy analysis was performed as described previously. ${ }^{52}$ Briefly, the thin films were placed under the microscope objective, and Raman (In Via Reflex, Renishaw) point-by-point mapping measurements were performed on the samples. The sample was irradiated with a $514 \mathrm{~nm}$ argon-ion laser, and a $\times 50$ or $\times 100$ objective lens was used to collect the backscattered light. Measurement scans were analyzed with the band-target entropy minimization (BTEM) algorithm. The spatial distributions of each underlying constituent were then generated in a color intensity image representative of the size or distance of the film sample mapped in micrometer. PCTX showed strong and sharp Raman peaks at 620, 1006, 1605 and $1718 \mathrm{~cm}^{-1}$. PLGA showed strong and significant Raman peaks at 850, 879, 896, 1130, 1430, 1458 and $1770 \mathrm{~cm}^{-1}$. PEG400 showed a much broader relative Raman spectrum, with band maxima centered around 531, 812, 838, 891, 1060, 1137, 1244, 1286 and $1474 \mathrm{~cm}^{-1}$, whereas PEG10k showed strong and sharp Raman peaks at 366, 538, 585, 847, 862, 1065, 1128, 1144, $1233,1282,1399,1447,1473,1482$ and $1488 \mathrm{~cm}^{-1}$. The reference Raman spectra obtained from the respective pure components (namely, PCTX, PLGA, PEG10k and PEG400) can be found in Supplementary Figure 1.

In vitro film mechanical properties. Thin films $(30-40 \mu \mathrm{m})$ were prepared in rectangular strips $\left(8 \times 1 \mathrm{~cm}^{2}\right)$ according to the ASTM D882 standard for tensile testing. After the polyethylene terephthalate sheet was removed, each rectangular film was clamped onto submersible tensile water grips on an Instron Tester (Model 5567) with a load cell capacity of $10 \mathrm{~N}$. The samples were fully immersed in PBS medium maintained at $37^{\circ} \mathrm{C}$ to mimic physiological conditions. They were then subjected to tensile stress at a rate of $5 \mathrm{~mm} \mathrm{~min}^{-1}$. The data were plotted and analyzed with Bluehill software version 3.00 (Singapore, Singapore). Young's modulus $(E)$, yield strength $\left(\sigma_{\mathrm{ys}}\right)$, tensile stress at break $\left(\sigma_{\mathrm{b}}\right)$ and elongation at break $\left(\varepsilon_{\mathrm{b}}\right)$ were recorded in $\mathrm{MPa}$ and calculated in triplicate. A blueprint of the submersible tensile water grips and an overview of the mechanical evaluation setup are shown in Supplementary Figures 2 and 3 , respectively.

Film surface and cross-section morphology. Samples were coated with platinum for $50 \mathrm{~s}$ at $20 \mathrm{~mA}$ under a chamber pressure of $<5 \mathrm{~Pa}$ using a JEOL JFC1600 Auto Fine Coater, Tokyo, Japan. Secondary electron images of the film surfaces were acquired at $5.0 \mathrm{kV}$ and $12 \mu \mathrm{A}$ at a working distance of $8 \mathrm{~mm}$ using scanning electron microscopy (JEOL JSM-6360). Cross-sectional samples were embedded in Tissue-Tek optimal cutting temperature fluid before being cyromicrotomed into $10 \mu \mathrm{m}$ sections. Cross-sectioned samples were coated and imaged similarly.

Film degradation. Films were initially weighed $\left(W_{\mathrm{o}}\right)$ in triplicate before incubation in PBS maintained at $37^{\circ} \mathrm{C}$. At predetermined time points, the films were rinsed with deionized water, the excess was blotted off and they were measured to determine the wet weight $\left(W_{\text {wet }}\right)$. The samples were then dried thoroughly in a vacuum oven for at least 1 week before their dry weight $\left(W_{\text {dry }}\right)$ was measured gravimetrically. These dried samples were subsequently used to determine the MW decay of PLGA films by measuring the number-average MW (Mn) of samples using size exclusion chromatography with a Shimadzu LC-20AD HPLC (Kyoto, Japan) equipped with an RI detector and column heater set at $35^{\circ} \mathrm{C}$. Low polydispersity polystyrene standards (Fluka) from $580-400000 \mathrm{kDa}$ were used to calibrate the three linear PLgel $(5 \mu \mathrm{m})$ mixed C 
columns (Varian, Singapore, Singapore). HPLC grade chloroform was used as the mobile phase at a flow rate of $1.0 \mathrm{ml} \mathrm{min}^{-1}$.

Water absorption and weight loss were calculated as follows:

$$
\begin{aligned}
& \text { Water absorption }(\%)=\frac{W_{\text {wet }}-W_{\text {dry }}}{W_{\text {dry }}} \times 100 \% \\
& \text { Weight loss }(\%)=\frac{W_{\mathrm{o}}-W_{\text {dry }}}{W_{\mathrm{o}}} \times 100 \%
\end{aligned}
$$

In vitro PEG release quantified by ${ }^{1} H N M R$. Films were immersed in $2 \mathrm{ml}$ of phosphate buffered saline (PBS) in triplicate. At predetermined time points, aliquots were taken and completely lyophilized. The lyophilized content in the tube was dissolved in $1050 \pm 10 \mu \mathrm{g}(700 \mu \mathrm{l})$ of $\mathrm{CDCl}_{3}$ for at least $1 \mathrm{~h}$, vortexed and centrifuged at 10000 r.p.m. for $5 \mathrm{~min}$. The ${ }^{1} \mathrm{H}$ NMR (nuclear magnetic resonance) spectra of the supernatant were recorded on a Bruker Advance Spectrometer (Bruker, Billerica, MA, USA) at $400 \mathrm{MHz}$ using the signal of tetramethysilane present in deuterated chloroform at $0.03 \% \mathrm{v} / \mathrm{v}$ as an internal standard. ${ }^{1} \mathrm{H}$ NMR $(400 \mathrm{MHz}, \mathrm{CDCl} 3, \delta)$ 1.5-1.7 (bs, PLGA 3H, -C(=O)$\mathrm{CH}(\mathrm{CH} 3)-\mathrm{O}-\mathrm{C}(=\mathrm{O})-\mathrm{CH} 2-\mathrm{O}-$, 3.45-3.85 (bs, PEG 4H, -O-CH2-CH2-O-, 4.6-5.0 (bs, PLGA 2H, -C(=O)-CH(CH3)-O-C(=O)-CH2-O-, 5.0-5.3 (bs, PLGA $1 \mathrm{H},-\mathrm{C}(=\mathrm{O})-\mathrm{CH}(\mathrm{CH} 3)-\mathrm{O}-\mathrm{C}(=\mathrm{O})-\mathrm{CH} 2-\mathrm{O}-$. The italics referred to the hydrogen atom of that compound that was used to calculate the mole ratios. The amount of PEG released was calculated based on the molar concentration of hydrogen atoms with respect to the tetramethysilane internal standard.

In vitro PCTX release quantified by HPLC. The in vitro release of PCTX was conducted in triplicate in $2 \mathrm{ml}$ of PBS spiked with $2 \%$ Tween 80 in release buffer $(\mathrm{pH} 7.4)$ at $37^{\circ} \mathrm{C}$. At predetermined time points, aliquots were withdrawn and filtered through a $0.2 \mu \mathrm{m}$ cellulose syringe filter. Sink conditions were maintained throughout the release. PCTX was quantified with an Agilent Series 1100 HPLC (Santa Clara, CA, USA) equipped with a UV/Vis detector set at $227 \mathrm{~nm}$ and an autosampler. A total dissolution quantification of the $1 \times 1 \mathrm{~cm}^{2}$ samples was conducted in triplicate by dissolving the films in acetone. The solubility limit of PCTX in PBS/2\% Tween 80 buffer was determined to be $20 \mu \mathrm{g} \mathrm{ml}^{-1}$.

\section{Statistics}

Statistical analysis was performed with IBM SPSS Statistics 19 software. Oneway ANOVA was used to determine differences among the formulation groups, and pairs were compared using post-hoc Tukey's multi-comparison test. A Pearson product-moment correlation coefficient (Pearson's correlation $(r)$ ) was also computed to assess the relationship and strength of correlation between any two variable factors that might influence the release of PEG additives and PCTX. A value of $P<0.01$ or $P<0.05$ was considered statistically significant. It should be noted that the data analysis and conclusions from the trend lines and correlations drawn in this study are only valid for the range of data tested here.

\section{RESULTS}

\section{Raman mapping and BTEM analysis}

Each pre-processed Raman mapping data set was subjected to BTEM analysis to reconstruct the underlying pure component spectra and their associated spatial distributions. BTEM analysis revealed a homogeneous distribution of PCTX within the PLGA, as shown in the spatial mapping on the right in Figure 1a. The image represents the relative intensities of the respective components measured by the distance mapped in micrometer. A high intensity for a particular component is represented by warmer colors, that is, red on the mapping, while a low concentration is represented by cooler colors, that is, blue. Polyethylene terephthalate, which was used in the casting of PLGA films for easy handling, was easily separated out and reconstructed in the first component spectrum. The second component spectrum showed combined Raman peaks from PCTX and PLGA; this combination indicated that there was compositional co- linearity between these two components, because there was no spectral variation between them that could facilitate their separation via BTEM analysis. Therefore, it is likely that PCTX was homogeneously distributed throughout the PLGA film.

When the short chain additive PEG400 was incorporated into the PCTX-PLGA films, the reconstructed spectrum exhibited combined Raman peaks of PCTX and PEG400, as shown in Figure 1b. This finding indicated that there was some extent of association or colocalization between these two components that caused them to be inseparable via BTEM analysis. The presence of PEG400 caused PCTX to be preferentially associated with PEG400, which then formed small random domains in the continuous PLGA film that showed higher intensities of PCTX and PEG400, as indicated by the red regions in the first spatial mapping in Figure $1 b$.

Similar spectral and spatial distributions were also observed for PCTX-PLGA films incorporating the long-chain additive PEG10k. However, significantly larger domains with higher intensities of PCTX and PEG10k were observed, as shown in the first spatial mapping in Figure 1c. The spatial mappings also indicated larger and more obvious phase separation of long-chain PEG10k in PCTX-PLGA films compared with short chain PEG400. The extent of phase separation between PCTX and PEG was therefore dependent on the chain length or MW of the PEG additives. Consequently, this large phase separation could influence the physicochemical characteristics, degradation and release mechanisms of PEG-incorporated PCTXPLGA films.

\section{In vitro mechanical properties}

To mimic the hydration that occurs under physiological conditions as closely as possible, a tensile water grip and bath setup was designed to maintain film samples in a constant aqueous environment at $37^{\circ} \mathrm{C}$, as shown in Supplementary Figure 3. This conditioning system allowed the mechanical evaluation of thin films under constant hydration, which more accurately represents the mechanical characteristics of these films, particularly when the end application involves implantation. Mechanical properties including elastic modulus $(E)$, yield strength $\left(\sigma_{\mathrm{ys}}\right)$, tensile strength $\left(\sigma_{\mathrm{b}}\right)$ and elongation at break $\left(\varepsilon_{\mathrm{b}}\right)$ were tested and recorded under constant aqueous buffered conditions at $37^{\circ} \mathrm{C}$.

PCTX-PLGA films showed an overall reduction in mechanical properties vs films tested in the dry state, as shown in Figure 2. The hydrated PCTX-PLGA films experienced a significant reduction in the modulus, as represented by the substantial change in the slope of the stress-strain plot between 1 and $10 \%$ strain, and a large drop in tensile strength of $\sim 4 \mathrm{MPa}$ was also observed. The presence of an aqueous environment with the temperature maintained at $37^{\circ} \mathrm{C}$ exerted a plasticizing effect on the mechanical properties of the PCTX-PLGA films. ${ }^{53-55}$ These hydrated films were therefore able to withstand greater strain or elongation before breaking in the presence of water.

The mechanical properties of hydrated PCTX-PLGA films incorporated with PEG additives are summarized in terms of their Young's modulus $(E)$ in $\mathrm{MPa}$ and by the percentage of elongation at the break point $\left(\varepsilon_{\mathrm{b}}\right)$, as shown in Table 1 . The Young's modulus indicates the stiffness of the films and was calculated by the slope of the stressstrain curve between 1 and $10 \%$ strain. The amount of strain that these films could withstand up to their respective break points was measured by the percentage of elongation. The incorporation of PEG additives did not change the modulus of PCTX-PLGA films up to a $30 \mathrm{wt} \%$ additive concentration, but it had resulted in an overall reduction in the elongation of these films. In the presence of PEG 

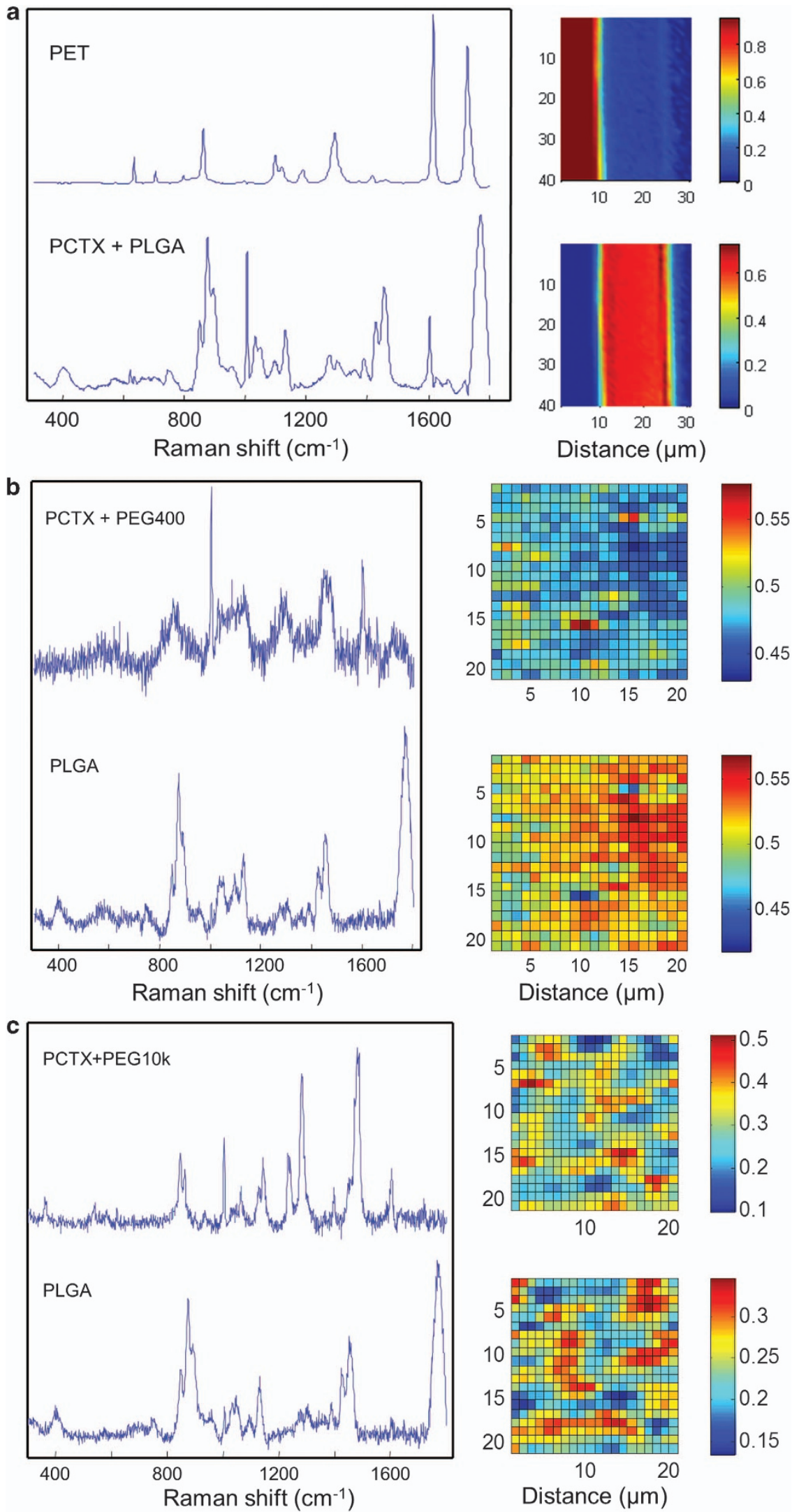

Figure 1 Raman spectra and microscopy mapping of (a) paclitaxel (PCTX)-poly( $\left(_{D, L}\right.$-lactic-co-glycolic acid) (PLGA) film blended with (b) poly(ethylene glycol)400 (PEG400) and (c) PEG10k at 30 wt\% with respect to PLGA. Raman scans were collected in a spectral window from 300 to $1800 \mathrm{~cm}^{-1}$, and the corresponding spatial distributions of the components are mapped on the right in terms of the distance in $\mu \mathrm{m}$ for both the $x$ and $y$ axes. A high intensity for a particular component is indicated by red on the spatial mapping on the right, which corresponds to its Raman spectrum on the left. 


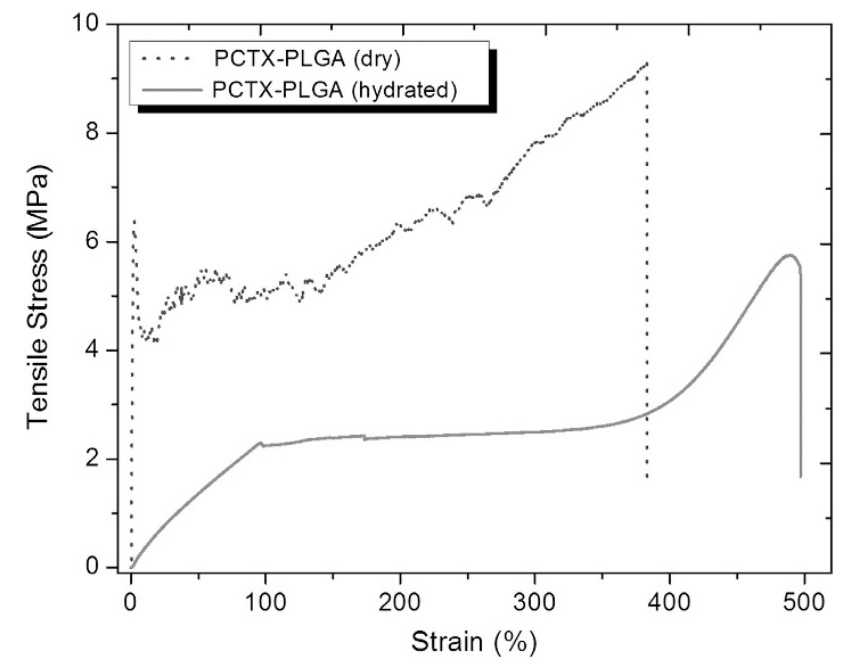

Figure 2 Representative stress versus strain plot of paclitaxel (PCTX)poly( $D_{D, L}$-lactic-co-glycolic acid) (PLGA) films evaluated under dry and hydrated conditions. An overall reduction in the mechanical properties was observed with hydrated PCTX-PLGA film. An increase in strain was observed in the hydrated PCTX-PLGA film due to the plasticizing effect of water.

Table 1 Summary of the mechanical and degradation properties

\begin{tabular}{lllcc}
\hline $\begin{array}{l}\text { PCTX-PLGA film } \\
\text { samples }\end{array}$ & $\mathrm{E}(\mathrm{MPa})^{\mathrm{b}}$ & $\varepsilon_{b}(\%)^{\mathrm{c}}$ & $\begin{array}{c}\text { Degradation rate con- } \\
\text { stant } \mathrm{k}(\text { per day) }\end{array}$ & $\begin{array}{c}\text { Linear regres- } \\
\text { sion }\left(\mathrm{R}^{2}\right)^{\mathrm{e}}\end{array}$ \\
\hline PCTX-PLGA & $3.4 \pm 0.2$ & $496 \pm 9$ & $0.063 \pm 0.005$ & 0.981 \\
(control) with & & & & \\
10\% PEG400 & $3.2 \pm 0.1485 \pm 1$ & $0.051 \pm 0.004$ & 0.813 \\
20\% PEG400 & $3.8 \pm 0.2402 \pm 17$ & $0.040 \pm 0.010$ & 0.903 \\
30\% PEG400 & $3.3 \pm 0.3418 \pm 2$ & $0.032 \pm 0.002$ & 0.973 \\
10\% PEG10k & $2.7 \pm 0.1502 \pm 17$ & $0.035 \pm 0.002$ & 0.988 \\
20\% PEG10k & $2.6 \pm 1.1473 \pm 2$ & $0.024 \pm 0.001$ & 0.998 \\
30\% PEG10k & $3.1 \pm 0.1422 \pm 22$ & $0.021 \pm 0.001$ & 0.978 \\
\hline
\end{tabular}

Abbreviations: PCTX, paclitaxel; PEG, poly(ethylene glycol); PLGA, poly( ${ }_{D, L}$-lactic-co-glycolic acid).

aPCTX-PLGA films incorporated with PEG at concentrations from 10-30\%w/w.

'The Young's modulus $(E)$ was measured under constant hydration.

cPercentage of elongation at break $\left(\sigma_{\mathrm{b}}\right)$ was measured under constant hydration.

The degradation rate constant $(k)$ shows the absolute rate of molecular weight decay of these

films and PCTX-PLGA control film exhibited the fastest rate of degradation.

eLinear regression towards degradation rate constant $(k)$ was fitted using least squares

approach.

additives, the stress of these films could withstand up to their respective break point was also measured, as shown in Figure 3. All of the films experienced significant reductions in their tensile strengths after 2 weeks of in vitro degradation when compared with their corresponding tensile strengths measured at day 0 . The reduction in tensile strength at 2 weeks was greater in the presence of additives. This result could be due to the dissolution of phaseseparated domains, which left behind pores within the film matrix that contributed to the overall reduction in tensile strength of these films.

Cross-sectional morphology of films

The extent of the film degradation can be described qualitatively by changes observed in the cross-sectional morphology, as shown in Figure 4. The incorporation of PEG additives at $30 \mathrm{wt} \%$ and the subsequent dissolution upon immersion in the medium introduced pores in these PCTX-PLGA films when compared with the control

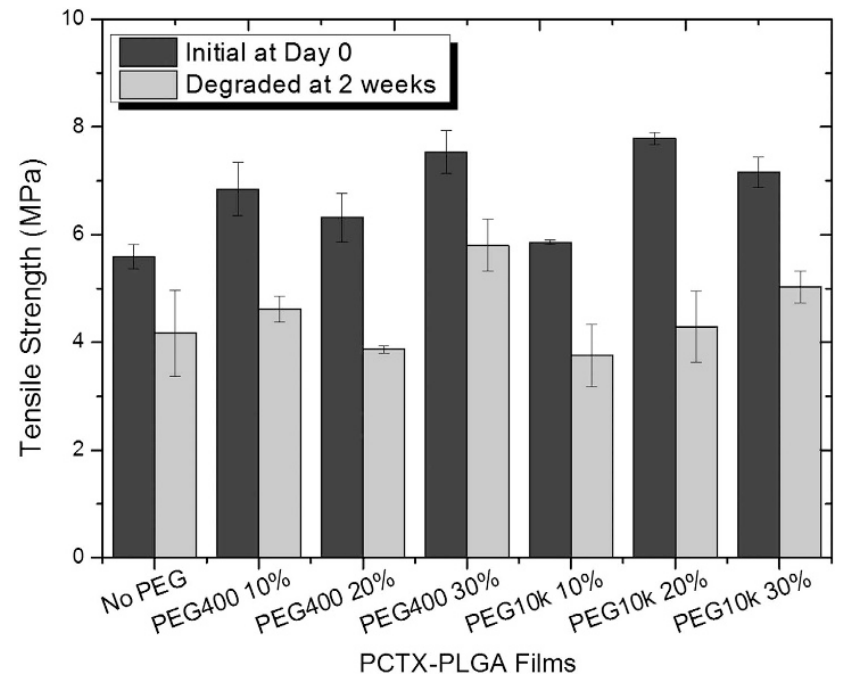

Figure 3 Tensile strength of paclitaxel (PCTX)-PLGA films incorporating poly(ethylene glycol) (PEG) additives at varying concentrations evaluated under hydrated conditions. Significant reductions in the tensile strength of films after 2 weeks of in vitro degradation were observed with respect to their corresponding initial tensile strengths $(P<0.05)$.

PLGA film initially and after 2 weeks. The pores observed in the initial scanning electron microscopy micrographs in the first column in Figure 4 were speculated to be occupied by solvent-hydrated PEG additives that were phase-separated from the PLGA matrix upon film casting. The final porous morphology of PEG-incorporated films was therefore obtained after the drying process. No pores were initially observed with the absence of PEG additive in PCTX-PLGA film before the start of degradation. Subsequently, some pores were observed in this PCTX-PLGA film at 2 weeks into degradation. Extensive porosity was observed in films incorporated with PEG at $30 \mathrm{wt} \%$ at 2 weeks. The initial porosity of these PEG-incorporated films enhanced the influx of water molecules, which allowed the dissolution of PEG additives and thereby resulted in extensive porous films at 2 weeks, as shown in the second column of Figure 4. The increase in porosity of the PEG-incorporated films could have contributed to the overall reduction in their tensile strengths at 2 weeks, as seen in Figure 3.

\section{Effects of PEG on PLGA degradation}

The degradation of PCTX-PLGA films incorporated with PEG additives was monitored in terms of water uptake and mass loss under in vitro conditions, as shown in Figure 5. The amount of water absorbed by the films incorporated with short chain PEG400 at $30 \mathrm{wt} \%$ was found to be $40 \%$ higher by the first day compared with the amount absorbed by the PCTX-PLGA control film (Figure 5a). Owing to the strongly hydrophilic diol character of short chain PEG400 additives, the amount of water absorbed was approximately three times higher than in the films incorporating long-chain PEG10k additives at the same additive concentration. The amount of water absorbed by the films incorporating PEG10k at $30 \mathrm{wt} \%$ was only $\sim 15 \%$ higher than the control at the first time point, as shown in Figure $5 \mathrm{~b}$. As pores were already prominent in films incorporating PEG additives, the water uptake in these films remained fairly constant up to 35 days. The PCTX-PLGA control film showed a gradual increase in the amount of water absorbed up to $15 \%$ by day 35 because pores that could entrap more water were only noticeable $\sim 2$ weeks into the degradation (Figure 4). 


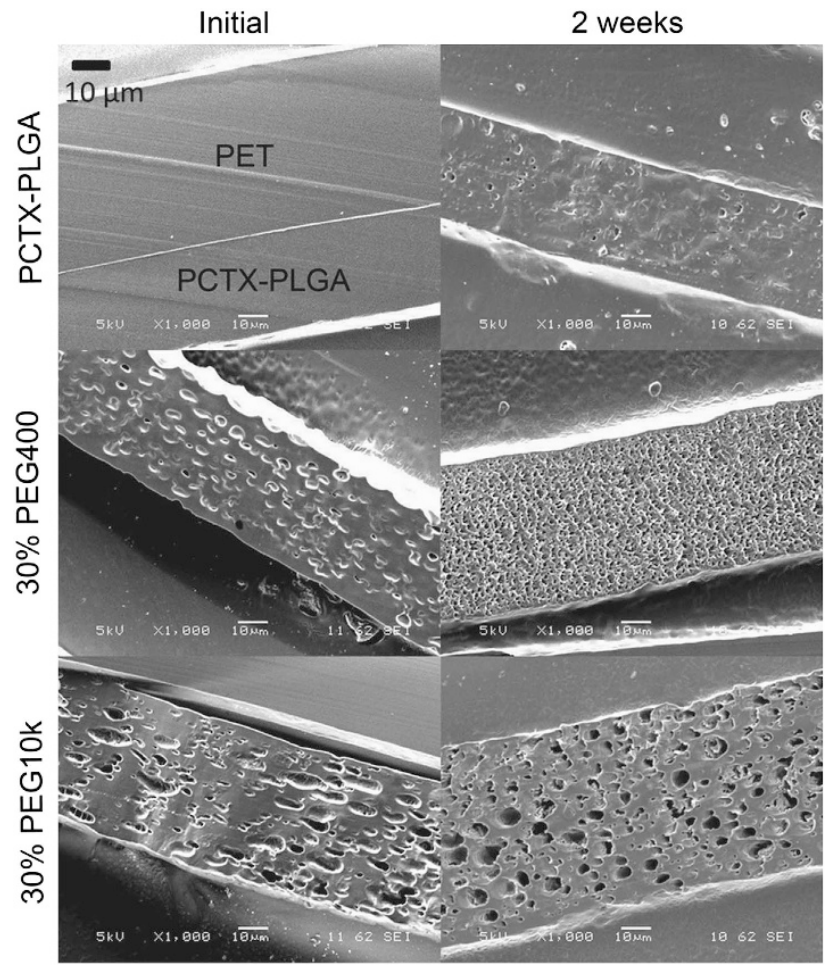

Figure 4 Surface and cross-sectioned scanning electron microscopy (SEM) micrographs ( $\times 1000$ magnification) of paclitaxel $(P C T X)$-poly $\left(_{D, L}\right.$-lactic-coglycolic acid) (PLGA) films that incorporate $30 \mathrm{wt} \%$ poly(ethylene glycol)400 (PEG400) and PEG10k at the beginning and after 2 weeks of degradation. The presence of pores was seen in films incorporating additives, and larger pores were observed for the longer chain PEG10k additive.

Although the PCTX-PLGA control film had negligible mass loss over a period of 35 days, films incorporated with PEG400 at $30 \mathrm{wt} \%$ showed a slight increase in mass loss of up to $12 \%$ during its degradation period, as shown in Figure $5 \mathrm{c}$. The initial mass loss from these films remained below $5 \%$. Conversely, films incorporated with PEG10k at $30 \mathrm{wt} \%$ showed double this amount of initial mass loss up to $\sim 10 \%$ at day 1 in Figure $5 \mathrm{~d}$. This large amount of mass loss could be related to the dissolution of the phase-separated PEG-rich domains from the PLGA films.

The decrease in the weighted-number-average MW (Mn) with longer degradation time indicates chain scission of the ester bonds due to hydrolysis in the PLGA backbone. The first-order degradation rate constants $(k)$ were calculated from a linear regression analysis of the semilog plot of Mn vs time. The degradation rate constants $(k)$ and their corresponding linear regression coefficients for each film are summarized in Table 1 . In the absence of any PEG additive, the PCTX-PLGA control film exhibited the fastest degradation despite its low water uptake and mass loss (Figure 7). This finding can be attributed to the accumulation of acidic byproducts of hydrolysis, which further catalyze the degradation of the PCTX-PLGA film. The initial porosity in films incorporating PEG additives could have enhanced water penetration and, therefore, reduced the accumulation of the acidic byproducts that contributed to the autocatalysis of PLGA. Consequently, slower degradation rates were recorded for films incorporating PEG additives, as summarized in Table 1. Interestingly, the slowest degradation rate corresponded to films incorporating $30 \mathrm{wt} \%$ PEG10k additive, which showed large and extensive porosity with high mass loss. Degradation byproducts can therefore diffuse out of PEG-incorporated films through water-filled pores and channels.

\section{Effects of PEG on PCTX release}

PEG additives were incorporated into PCTX-PLGA films to enhance the typical slow release associated with hydrophobic drugs in hydrophobic polymer systems. Aliquots from the respective dissolutions of PEG400 and PEG10k were analyzed with ${ }^{1} \mathrm{H}$ NMR, and cumulative releases plotted against degradation time are shown in Figure 6. PCTX-PLGA films incorporating the short chain additive showed increased rates with increased concentrations of PEG400 over the first 7 days, as shown in Figure 6a. Despite the fast release rates of PEG400 additive, the burst release remained below $100 \mu \mathrm{g} \mathrm{cm}^{-2}$ even at $30 \mathrm{wt} \%$ concentration. By contrast, films incorporating the longchain additive showed little variation in release rates with increasing concentrations of PEG10k, as shown in Figure 6b. Interestingly, a distinctive burst release was observed with increasing concentrations of PEG10k despite similar release rates. The burst release at $30 \mathrm{wt} \%$ of PEG10k was $500 \mu \mathrm{g} \mathrm{cm}^{-2}$, which is approximately five times that of the burst release obtained for PEG400 at the same concentration. The subsequent release rates of PEG400 and PEG10k were almost the same after day 7 and across the three different concentrations. The release profiles of PEG additives seemed to show significant differences during the initial phase of dissolution between 0 and 7 days. This result can be attributed to the extent of phase separation observed with the Raman spatial mappings (Figure 1), which can be used to explain the differences in dissolution characteristics between short and long-chain additives resulting in the PEG release profiles that were obtained.

Concurrently, the aliquots taken were also analyzed to measure the release of PCTX from the PEG-incorporated films and the PCTXPLGA control film. The respective cumulative release profiles were plotted against degradation time, as shown in Figure 7. The PCTXPLGA control film, in the absence of PEG additives, generally showed minute releases of PCTX with time, with only $\sim 7 \mu \mathrm{g} \mathrm{cm}^{-2}$ of PCTX released after 42 days. The release of PCTX was enhanced with increasing concentrations of both PEG400 and PEG10k. With the incorporation of short chain additives at $30 \mathrm{wt} \%$, only $\sim 13 \mu \mathrm{g} \mathrm{cm}^{-2}$ of PCTX burst release was obtained, as shown in Figure 7a. By contrast, a significantly larger burst release of PCTX of $\sim 32 \mu \mathrm{g} \mathrm{cm}^{-2}$ was obtained in films incorporating the long-chain PEG10k at $30 \mathrm{wt} \%$, as shown in Figure $7 \mathrm{~b}$; this outcome coincided with the large burst release of PEG10k, as seen in Figure 6b. Similar to the release of additives, PCTX release occurred in two phases under the influence of PEG additives. In the absence of PEG additives, the release of PCTX was limited by the degradation of the PLGA. As PLGA undergoes bulk degradation, limited release of PCTX was obtained until the PLGA film started to show significant mass loss. The initial slow release of PCTX in the first phase was therefore enhanced by the presence of additives through dissolution and diffusion of the associated PCTX and PEG. Subsequently, the release profiles became similar to that of the control film once most of the additives that were associated with PCTX had been released.

The coincidence in the parallel release of PEG and PCTX could imply that they are possibly associated with each other within the phase-separated domains of the PLGA film. To test this hypothesis, the obtained release data were further analyzed by plotting the release of PCTX against the release of PEG additives to determine the strength of correlation between their releases at varying concentrations (Figure 8). The increase in additive release generally corresponded to the increase in PCTX release. This increase was distinct and 

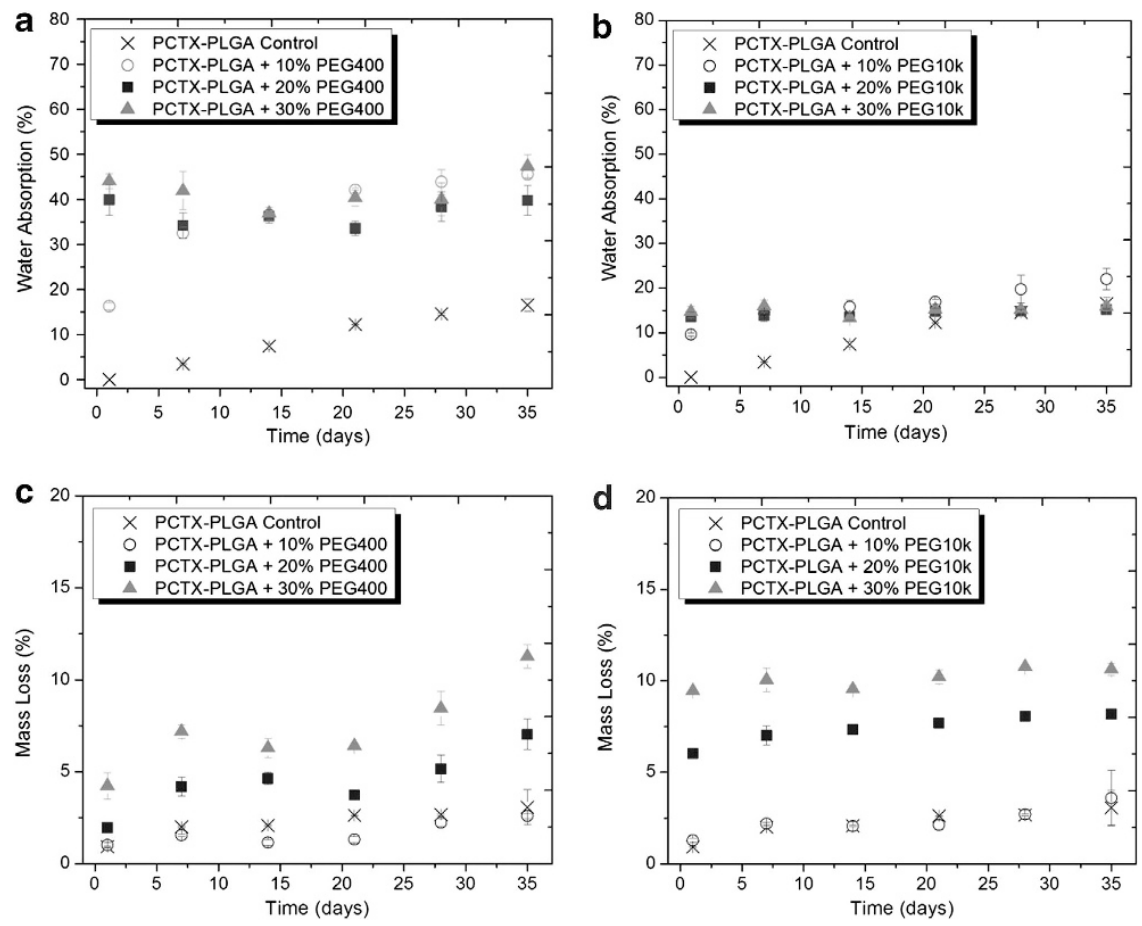

Figure 5 Degradation was monitored in terms of water uptake of the paclitaxel (PCTX)-poly $\left(_{D, L}\right.$-lactic-co-glycolic acid) (PLGA) films incorporating (a) poly(ethylene glycol)400 (PEG400) and (c) PEG10k. The corresponding mass loss from PCTX-PLGA films was also recorded for (b) PEG400 and (d) PEG10k additives. Significantly higher water uptake was observed for short chain PEG400 additives. Owing to the large phase-separated PEG-rich domains, greater mass loss was observed with PCTX-PLGA films incorporating PEG10k additives.

significant in the samples with long-chain PEG10k additives, as shown by the increasingly steeper slope at increasing additive concentrations in Figure 8b. As the phase-separated domains in PLGA films were larger with PEG10k, the extent of association between PCTX and PEG10k could possibly be greater than with PEG400. Consequently, larger pores, greater mass loss and therefore higher burst releases of PEG10k and PCTX were observed as a result of their stronger correlation compared to PEG400.

\section{DISCUSSION}

The properties of bioresorbable PCTX-PLGA films can be modulated through various formulations that incorporate PEG additives. Films that incorporate PEG additives at varying concentrations and MW experience variable physicochemical characteristics, degradation rates and drug release profiles. PCTX was found to be homogeneously distributed throughout the PLGA and co-localized in PEG domains, which were phase-segregated in the continuous PLGA film matrix in the Raman spatial mapping experiment (Figure 1). This feature has been described previously by Huang et al. ${ }^{56}$ With increasing additive concentrations and $\mathrm{MW}$, a larger extent of phase separation was noted with greater association of PCTX with PEG10k than with PEG400. This association increased the overall solubility and dissolution of these PCTX-additive-rich domains; in turn, the release of hydrophobic PCTX from the hydrophobic PLGA film was enhanced. The association between PCTX and PEG was supported by the corresponding burst releases of PEG10k (Figure 6) and PCTX (Figure 7) and by the greater initial mass loss (Figure 5) as a result of dissolution of the largely phase-separated domains with PEG10k additives. The associated PCTX and PEG additives enhanced the typical slow release of PCTX from PLGA films through dissolution and diffusion, which are two processes that would otherwise be limited by the degradation of PLGA. The hydrophilic effect of PEG additives on the release of PCTX was diminished after the first week. The subsequent release of PCTX was limited by the degradation of PLGA as most of the hydrophobic PCTX remained distributed within the hydrophobic PLGA matrix. Moreover, PCTX has poor aqueous solubility, and it is therefore unlikely to be released by diffusion through the pores generated by PEG additives. Consequently, the release profiles of PCTX from PEG-incorporated films observed in the second phase of release were almost identical to that of the PCTXPLGA control film.

The three hydroxyl groups and one amide group on PCTX can potentially associate with PEG additives through the formation of hydrogen bonds. ${ }^{57-60}$ The preferential association of PCTX with PEG was observed by coherent anti-stokes Raman scattering microcopy by Kang et al., ${ }^{61}$ and this association was validated by the disappearance of the sharp crystallization peaks of PEG under XRD in the presence of PCTX.61 Here, the association between PCTX and PEG was qualified by the strong positive correlations between the parallel release of PCTX and PEG (Figure 8). This correlation also showed a dependence on the concentration of the PEG additives, particularly with PEG10k. An understanding of the influence of additives on the release mechanisms and kinetics is important in the prediction of drug release behaviors from PLGA under physiological conditions. As the simultaneous release of additives and drugs is rarely reported in the literature, our findings should therefore open more avenues to modulate and predict drug release characteristics with the use of additives, particularly in the local delivery of hydrophobic drugs such as PCTX from hydrophobic polymer-based delivery systems.

In addition to an understanding of the phase distribution and its effects on the delivery of PCTX, the degradation characteristics of the resultant PLGA films are equally important for drug delivery systems 

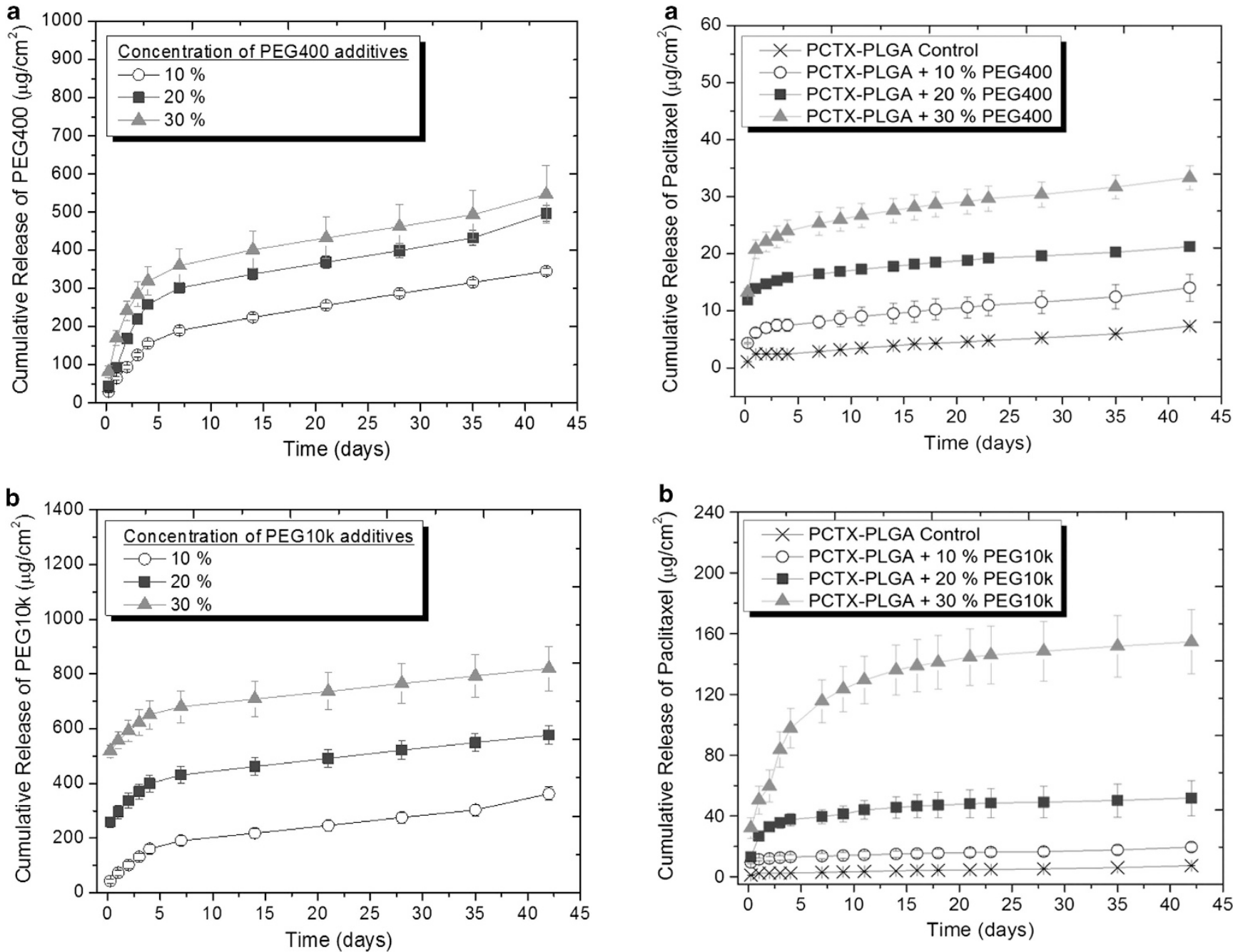

Figure 6 Cumulative release profiles of poly(ethylene glycol) (PEG; $\mu \mathrm{g} \mathrm{cm}^{-2}$ ) vs degradation time from paclitaxel (PCTX)-poly( $\left(_{0,1}\right.$-lactic-co-glycolic acid) (PLGA) films incorporating (a) PEG400 and (b) PEG10k at varying concentrations. The release rates showed a significant difference for short chain PEG400 additives, while the burst release increased significantly with increased concentrations of long-chain PEG10k.

that are designed for long-term treatment. There are many factors governing the degradation of PLGA including the lactide-to-glycolide (LA:GA) ratio, MW, end-group capping, $\mathrm{pH}$ of the surrounding medium, size, shape and porosity ${ }^{43,51,62,63}$ PEG additives gave rise to extensively porous films (Figure 4 ) that resulted in greater uptake and penetration of water molecules (Figure 5). A quicker degradation was therefore anticipated in films incorporated with PEG additives. However, the degradation rates were retarded in these PEG-incorporated films (Table 1). As PLGA is known to undergo bulk degradation, a decrease in MW with time was obtained with negligible change in mass loss. During its degradation, hydrolysis of the PLGA backbone generates lactic and glycolic acid byproducts that remain trapped within the PLGA film in the absence of pores. The accumulation of these acidic byproducts within the film matrix then further catalyzes the hydrolysis of the PLGA backbone, a phenomenon commonly referred to as autocatalysis. ${ }^{64-66}$ Hence, the fastest degradation rate (0.063 per day) was observed in the PCTX-PLGA control film. In the presence of extensive porosity in PLGA films due to the incorporation and dissolution of PEG additives, these acidic byproducts were able to

Figure 7 Cumulative release profiles of paclitaxel (PCTX) vs degradation time from PCTX-poly $\left({ }_{D, L}\right.$-lactic-co-glycolic acid) (PLGA) films incorporating (a) poly(ethylene glycol)400 (PEG400) and (b) PEG10k at varying concentrations. More significant variations in PCTX release were observed with long-chain PEG10k compared with PEG400. All release profiles were observed to proceed at similar rates after $\sim 15$ days.

diffuse out of the film through these water-filled pores or channels. Consequently, the autocatalysis in PLGA was suppressed by the diffusion of acidic byproducts through the water-filled pores, which explains the significant reduction in the degradation rates of films incorporating PEG additives. The degradation rate of PLGA exhibited a dependence on the concentration of the additives that may be related to the extent of porosity in the films, as determined by the phase separation of the PEG additives within the PLGA matrix. The slowest degradation ( 0.021 per day) occurred in the PEG10kincorporated film, which also showed large and obvious domains that were phase-separated from the PLGA matrix at $30 \mathrm{wt} \%$ concentration of PEG10k (Figure 1). The degradation of PLGA films can therefore be modulated by the concentration and MW of PEG additives as these parameters were directly related to the extent of phase separation and the resultant porosity in these films. ${ }^{67-70}$

With the dynamically changing characteristics of degrading PLGA films in the presence of hydrophilic PEG additives, it is essential to carefully assess the mechanical characteristics of these films. Most of the literature lacks such a robust system, and many studies have 

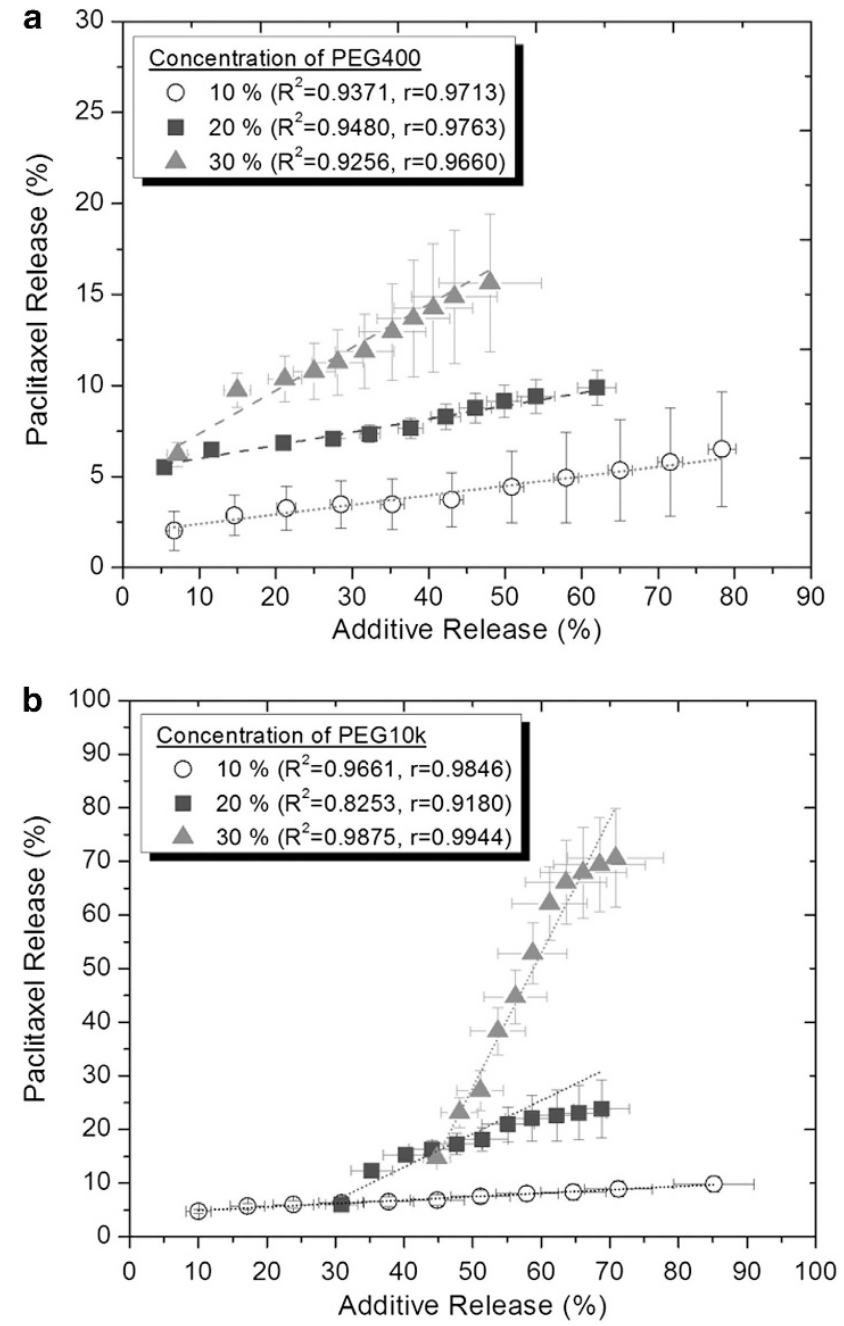

Figure 8 Correlation plots of percentage paclitaxel release with additive release taken at identical time points for paclitaxel (PCTX)-poly $\left(_{D, L}\right.$-lactic-coglycolic acid) (PLGA) films incorporating (a) poly(ethylene glycol)400 (PEG400) and (b) PEG10k additives at varying concentrations. The linear regression coefficient is denoted by $R^{2}$, and the Pearson's correlation coefficient is denoted by $r$ in the legend. A maximally strong association or correlation between two variables is given by $r=1$.

shown to merely subject their test subjects to some minimal form of hydration before mechanical evaluation. A constant level of hydration is often not maintained throughout the mechanical test. To have a better understanding of the behavior of various PEG-incorporated films in this study, the mechanical tests were conducted under constant in vitro conditions to mimic the hydration and temperature of physiological conditions as closely as possible. Under constant aqueous environment, the films acquire some degree of elasticity or softening from the plasticizing effect of water molecules, and they tend to be able to stretch more than when they are in their dry state. As such, the hydrated PLGA films were accompanied by an overall reduction in stiffness and tensile strength. The mechanical properties of PLGA films incorporating PEG additives were re-evaluated at 2 weeks after degradation. There have been few attempts at a mechanical evaluation of degraded bioresorbable polymer films. Here, a significant reduction in tensile strength was observed for all the degraded PCTX-PLGA films, particularly those that incorporated PEG additives. Owing to the extensive porosity resulting from the phase separation and dissolution of the additive-rich domains, the PEG-incorporated films became weaker and could not withstand as much stress loading compared with their initial characteristics. Therefore, they failed at much lower stress loadings. Such considerations have to be taken into account, especially in the development of drug delivering implants, which require a certain amount of mechanical strength at the site of application. It is therefore important to accurately evaluate films or scaffolds that are designed for use in an aqueous environment, because it has been shown that bioresorbable PLGA films respond very differently in their dry and hydrated states.

\section{CONCLUSIONS}

This study reports on the influence of hydrophilic PEG additives on the mechanical properties and degradation of, as well as drug release from, PCTX-PLGA films. As a result of the incorporation of blended additives, phase separation was observed. The resulting effect on drug delivery and film properties brought about by this phase separation has been neither studied in-depth nor fully understood. This phaseseparated system was carefully characterized, and original mechanisms governing the parallel release of both additives and PCTX were proposed. The simultaneous release of PEG additives and PCTX showed strong statistical correlations, and the phase separation as a result of blending was exploited to enhance the release of hydrophobic PCTX from PLGA films. The data obtained therefore allowed for the control and modulation of the release of PCTX from PLGA films in the lag phase, which is commonly observed with hydrophobic drugpolymer systems. In addition, the autocatalysis of PLGA was suppressed by extensive porosity in PEG-incorporated films, because acidic byproducts of the degradation were allowed to diffuse away through water-filled pores and channels. The mechanical characteristics of this blended system were also evaluated under constant aqueous hydration. This study has reported new and detailed information with regards to the design, preparation and characterization of localized drug delivery systems through the use of PEG additives, a topic that has been under-addressed in the literature to date.

\section{ACKNOWLEDGEMENTS}

This research was supported by the National Research Foundation (NRF) CRP 002-12 Grant "Biodegradable Cardiovascular Implants" and the Nanyang Institute of Technology in Health and Medicine (NITHM), NTU, Singapore. The first author would like to express her sincere thanks and appreciation to family and friends, and is grateful for the help and support offered by laboratory colleagues Kong Jen Fong, Esther Liu and Anthony Ng; students Tan Jun Zhi John and Ang Ren Jie; and technical staff Nelson Ng, Patrick Lai and Wilson Lim.

1 Vert, M., Li, S. M., Spenlehauer, G. \& Guerin, P. Bioresorbability and biocompatibility of aliphatic polyesters. J. Materials Sci. 3, 432-446 (1992).

2 Zentner, G. M., Rathi, R., Shih, C., McRea, J. C., Seo, M. H., Oh, H., Rhee, B. G., Mestecky, J., Moldoveanu, Z. \& Morgan, S. W. M. Biodegradable block copolymers for delivery of proteins and water-insoluble drugs. J. Control. Release 72, 203-215 (2001).

3 Athanasiou, K. A., Neiederauer, G. G. \& Agrawal, C. M. Sterilization, toxicity, biocompatibility and clinical applications of polylactic acid copolymers. Biomaterials 17, 93-102 (1996).

4 Wu, X. S. Synthesis and Properties of Biodegradable Lactic/Glycolic Acid Polymers (Marcel Dekker, New York, NY, USA, 1995).

5 Perugini, P., Genta, I., Conti, B., Modena, T. \& Pavanetto, F. Periodontal delivery of ipriflavone: new chitosan/PLGA film delivery system for a lipophilic drug. Int. J. Pharm. 252, 1-9 (2003).

6 Bromberg, L. E., Buxton, D. K. \& Friden, P. M. Novel periodontal drug delivery system for treatment of periodontitis. J. Control. Release 71, 251-259 (2001). 
7 Wang, Y., Challa, P., Epstein, D. L. \& Yuan, F. Controlled release of ethacrynic acid from poly(lactide-co-glycolide) films for glaucoma treatment. Biomaterials 25, 4279-4285 (2004).

8 Huang, S. F., Chen, J. L., Yeh, M. K. \& Chaing, C. H. Physicochemical properties and in vivo assessment of timolol-loaded poly(D,L-lactide-co-glycolide) films for long-term intraocular pressure lowering effects. J. Ocul. Pharmcol. Ther. 21, 455-53 (2005).

9 Kocbek, P., Obermajer, N., Cegnar, M., Kos, J. \& Kristl, J. Targeting cancer cells using PLGA nanoparticles surface modified with monoclonal antibody. J. Control. Release 120, 18-26 (2007)

10 Fonseca, C., Simões, S. \& Gaspar, R. Paclitaxel-loaded PLGA nanoparticles: preparation, physicochemical characterization and in vitro anti-tumoral activity. J. Control. Release 83, 273-286 (2002).

11 Westedt, U., Wittmar, M., Hellwig, M., Hanefeld, P., Greiner, A., Schaper, A. K. \& Kissel, T. Paclitaxel releasing films consisting of poly(vinyl alcohol)-graft-poly(lactideco-glycolide) and their potential as biodegradable stent coatings. J. Control. Release. 111, 235-246 (2006).

12 Engineer, C., Parikh, J. \& Raval, A. Effect of copolymer ratio on hydrolytic degradation of poly(lactide-co-glycolide) from drug eluting coronary stents. Chem. Eng. Res. Design 89, 328-334 (2011).

13 Wang, X. T., Venkatraman, S. S., Boey, Y. C. F., Loo, S. C. J. \& Tan, L. P. Effects of controlled-released sirolimus from polymer matrices on human coronary artery smooth muscle cells. J. Biomater. Sci. Polym. Ed. 18, 401-414 (2007).

14 Jackson, J. K., Smith, J., Letchford, K., Babiuk, K. A., Machan, L., Signore, P., Hunter, W. L., Wang, K. \& Burt, H. M. Characterization of perivascular poly(lactic-co-glycolic acid) films containing paclitaxel. Int. J. Pharm. 283, 97-109 (2004).

15 Manome, Y., Kobayashi, T., Mori, M., Suzuki, R., Funamizu, N., Akiyama, N., Inoue, S. Tabata, Y. \& Watanabe, M. Local delivery of doxorubicin for maglignant glioma by a biodegrdable PLGA polymer sheet. Anticancer Res. 26, 3317-3326 (2006).

16 Brem, H., Piantodosi, S., W. M. Burger, P. C., Selker, R., Vick, N. A., Black, K., Sisti, M., Brem, S., Mohr, G., Muller, P., Morawetz, R. \& Schold, S. C. Placebo-controlled trial of safety and efficacy of intraoperative controlled delivery by biodegradable polymers of chemotherapy for recurrent gliomas. Lancet 345, 1008-1012 (1995).

$17 \mathrm{Xu}, \mathrm{Q}$. \& Czernuszka, J. T. Controlled release of amoxicillin from hydroxyapatite-coated poly(lactic-co-glycolic acid) microspheres. J. Control. Release 127, 146-153 (2008).

18 Wang, Y., Challa, P., Epstein, D. L. \& Yuan, F. Controlled release of ethacrynic acid from poly(lactide-co-glycolide) films for glaucoma treatment. Biomaterials 25 , 4279-4285 (2004).

19 Bertoldi, C., Zaffe, D. \& Consolo, U. Polylactide/polyglycolide copolymer in bone defect healing in humans. Biomaterials 29, 1817-1823 (2008).

20 Meng, Z. X., Xu, X. X., Zheng, W., Zhou, H. M., Li, L., Zheng, Y. F. \& Lou, X. Preparation and characterization of electrospun PLGA/gelatin nanofibers as a potential drug delivery system. Colloids Surfaces B Biointerfaces 84, 97-102 (2011).

21 Fredenberg, S., Wahlgren, M., Reslow, M. \& Axelsson, A. The mechanisms of drug release in poly(lactic-co-glycolic acid)-based drug delivery systems-A review. Int. J. Pharm. 415, 34-52 (2011).

22 Wang, M., Feng, Q., Guo, X., She, Z. \& Tan, R. A dual microsphere based on PLGA and chitosan for delivering the oligopeptide derived from BMP-2. Polymer Degrad. Stabil. 96, 107-113 (2011)

23 Meng, Z. X., Zheng, W., Li, L. \& Zheng, Y. F. Fabrication, characterization and in vitro drug release behavior of electrospun PLGA/chitosan nanofibrous scaffold. Materials Chem. Phys. 125, 606-611 (2011).

24 Parveen, S. \& Sahoo, S. K. Long circulating chitosan/PEG blended PLGA nanoparticle for tumor drug delivery. Eur. J. Pharmacol. 670, 372-383 (2011)

25 Jain, G. K., Pathan, S. A., Akhter, S., Ahmad, N., Jain, N., Talegaonkar, S., Khar, R. K. \& Ahmad, F. J. "Mechanistic study of hydrolytic erosion and drug release behaviour of PLGA nanoparticles: Influence of chitosan,". Polymer Degrad. Stabil. 95, 2360-2366 (2010).

26 Feng, S. S., Mu, L., Win, K. Y. \& Huang, G. Nanoparticles of biodegradable polymers for clinical administration of paclitaxel. Curr. Med. Chem. 11, 413-424 (2004).

27 Belu, A., Mahoney, C. \& Wormuth, K. Chemical imaging of drug eluting coatings: Combining surface analysis and confocal Raman microscopy. J. Control. Release 126, 111-121 (2008).

28 Narayan, D. \& Venkatraman, S. S. Effect of pore size and interpore distance on endothelial cell growth on polymers. J. Biomed. Mater. Res. A. 87, 710-718 (2008)

29 Murphy, W. L., Peters, M. C., Kohn, D. H. \& Mooney, D. J. Sustained release of vascular endothelial growth factor from mineralized poly(lactide-co-glycolide) scaffolds for tissue engineering. Biomaterials 21, 2521-2527 (2000).

30 Ong, B. Y., Ranganath, S. H., Lee, L. Y., Lu, F., Lee, H. S., Sahinidis, N. V. \& Wang, C. $\mathrm{H}$. Paclitaxel delivery from PLGA foams for controlled release in post-surgical chemotherapy against glioblastoma multiforme. Biomaterials 30, 3189-3196 (2009).

31 Sundararajan, V. M. Principles of Biomedical Engineering (Artech House, Massachusetts, MA, USA, 2010).

32 Angelova, N. \& Hunkeler, D. Rationalizing the design of polymeric biomaterials. Trends Biotechnol. 17, 409-421 (1999).

33 Forrest, M. L., Won, C. Y., Malick, A. W. \& Kwon, G. S. In vitro release of the mTOR inhibitor rapamycin from poly(ethylene glycol)-b-poly([epsilon]-caprolactone) micelles. J. Control. Release 110, 370-377 (2006).

34 Ma, Y., Shi, F., Ma, J., Wu, M., Zhang, J. \& Gao, C. Effect of PEG additive on the morphology and performance of polysulfone ultrafiltration membranes. Desalination 272, 51-58 (2011).
35 Tan, L. P., Venkatraman, S. S., Sung, P. F., V. S. Wang, X. T., Boey, Y. C. F. \& Loo, S. C. J. Effect of plasticization on heparin release from biodegradable matrices. Int. J. Pharm. 283, 89-96 (2004).

36 Li, X. W., Lin, X. H., Zheng, L. Q., Yu, L., Lv, F. F., Zhang, Q. Q. \& Liu, W. C. Effect of poly(ethylene glycol) stearate on the phase behavior of monocaprate Tween 80 wate system and characterization of poly(ethylene glycol) stearate-modified solid lipid nanoparticles. Colloids Surfaces A Physiochem. Eng. Aspects 317, 352-359 (2008).

37 Essa, S., Rabanel, J. M. \& Hildgen, P. Effect of polyethylene glycol (PEG) chain organization on the physicochemical properties of poly(d, I-lactide) (PLA) based nanoparticles. Eur. J. Pharma. Biopharma. 75, 96-106 (2010).

38 Tooru O., J. L. \& P., Kinam Effects of ethylene glycol-based graft, star-shaped, and dendritic polymers on solubilization and controlled release of paclitaxel. J. Control. Release 93, 121-127 (2003).

39 Siepmann, F., Siepmann, J., Walther, M., M, R. J. \& Bodmeier, R. Polymer blends for controlled release coatings. J. Control. Release 125, 1-15 (2008).

40 Wang, N., Dong, A., Tang, H., Van Krik, E. A., Johnson, P. A. \& Murdoch, W. J. Synthesis of degradable functional poly(ethylene glycol) analogs as versatile drug delivery carriers. Macromol. Biosci. 7, 1187-1198 (2007).

41 Owen, G. R., Jackson, J. K., Chehroudi, B., Brunette, D. M. \& Burt, H. M. An in vitro study of plasticized poly(lactic-co-glycolic acid) films as possible guided tissue regeneration membranes: Material properties and drug release kinetics. J. Biomed. Mater. Res. A 95A, 857-869 (2010).

42 Manca, M. L., Loy, G., Zaru, M., Fadda, A. M. \& Antimisiaris, S. G. Release of rifampicin from chitosan, PLGA and chitosan-coated PLGA microparticles. Colloids Surfaces B Biointerfaces 67, 166-170 (2008).

43 Loo, S. C. J., Tan, J., Lee, W. L., Khoa, S. M., Chia, N. K., Venkatraman, S. S. \& Boey, Y. C. F. Hydrolytic degradation characteristics of irradiated multi-layered PLGA films. Int. J. Pharm. 360, 228-230 (2008).

44 Fredenberg, S., Wahlgren, M., Reslow, M. \& Axelsson, A. The mechanisms of drug release in poly(lactic-co-glycolic acid)-based drug delivery systems-a review. Int. J. Pharm. 415, 34-52 (2011).

45 Kang, J. \& Schwendeman, Steven P. Pore closing and opening in biodegradable polymers and their effect on the controlled release of proteins. Mol. Pharm. 4, 104-118 (2007)

$46 \mathrm{Wu}$, L., Zhang, J., Jing, D. \& Ding, J. "Wet-state” mechanical properties of three dimensional polyester porous scaffolds. J. Biomed. Mater. Res. A 76A, 264-271 (2006).

47 Axel, T. N., Giuseppe, T., Armin, A. \& Andreas, L. Controlled change of mechanical properties during hydrolytic degradation. Macrmol. Chem. Phys. 211, 182-194 (2010).

48 Lee, J., Kim, S., Heo, D., Kwon, I. \& Choi, B. J. In vitro characterization of nanofibrous PLGA/gelatin/hydroxyapatite composite for bone tissue engineering. Macromol. Res. 18, 1195-1202 (2010).

49 Zhang, X. F., O'Shea, H., Kehoe, S. \& Boyd, D. Time-dependent evaluation of mechanical properties and in vitro cytocompatibility of experimental compositebased nerve guidance conduits. J. Mech. Behav. Biomed. Mater. 4, 1266-1274 (2011).

50 Jackson, J. K., Owen, G. R., Chehroudi, B., Brunette, D. M. \& Burt, H. M. An in vitro study of plasticized poly(lactic-co-glycolic acid) films as possible guided tissue regeneration membranes: Material properties and drug release kinetics. J. Biomed. Mater. Res. A 95A, 857-869 (2010).

51 Kranz, H., Ubrich, N., Maincent, P. \& Bodmeier, R. Physicomechanical properties of biodegradable poly(D,L-lactide) and poly(D,L-lactide-co-glycolide) films in the dry and wet states. J. Pharm. Sci. 89, 1558-1566 (2000).

52 Widjaja, E., Kanaujia, P., Lau, G., Ng, W. K., Garland, M., Saal, C., Hanefeld, A Fischbach, M., Maio, M. \& Tan, R. B. H. Detection of trace crystallinity in an amorphous system using Raman microscopy and chemometric analysis. Eur. J. Pharma. Sci. 42, 45-54 (2011).

53 Blasi, P., D'Souza, S. S., Selmin, F. \& DeLuca, P. P. Plasticizing effect of water on poly(lactide-co-glycolide). J. Control. Release 108, 1-9 (2005).

54 Chen, T., Fowler, A. \& Toner, M. Literature review: supplemented phase diagram of the trehalose-water binary mixture. Cryobiology 40, 277-282 (2000).

55 Hancock, B. C. \& Zografi, G. The relationship between the glass transition temperature and the water content of amorphous pharmaceutical solids. Pharm. Res. 11, 471-477 (1994).

56 Huang, C., Steele, T., Widjaja, E., Boey, F., Venkatraman, S. \& Loo, J. The effect of polyethylene glycol structure on paclitaxel drug release and mechanical properties of PLGA thin films. Acta. Biomater. 7, 1973-1983 (2011).

57 Ozeki, T., Yuasa, H. \& Kanaya, Y. Application of the solid dispersion method to the controlled release of medicine. IX. Difference in the release of flurbiprofen from solid dispersions with poly(ethylene oxide) and hydroxypropylcellulose and the interaction between medicine and polymers. Int. J. Pharm. 155, 209-217 (1997).

58 Chutimaworapan, S., Ritthidej, G. C., Yonemochi, E., Oguchi, T. \& Yamamoto, K. Effect of water-soluble carriers on dissolution characteristics of nifedipine solid dispersions. Drug. Dev. Ind. Pharm. 26, 1141-1150 (2000).

59 Schachter, D. M., Xiong, J. C. \& Tirol, G. C. Solid state NMR perspective of drug polymer solid solutions: a model system based on poly(ethylene oxide). Int. J. Pharm. 281, 89-101 (2004).

60 Sato, T., Niwa, H., Chiba, A. \& Nozaki, R. Dynamical structure of oligo(ethylene glycol)s-water solutions studied by time domain reflectometry. J. Chem. Phys. 108 4138-4147 (1998). 
61 Kang, E., Robinson, J., Park, K. \& Cheng, J. X. Paclitaxel distribution in poly(ethylene glycol)/poly(lactide-co-glycolic acid) blends and its release visualized by coherent antistokes Raman scattering microscopy. J. Control. Release 122, 261-268 (2007).

62 Wahlgren, M., Fredenberg, S., Reslow, M. \& Axelsson, A. The mechanisms of drug release in poly(lactic-co-glycolic acid)-based drug delivery systems-a review. Int. J. Pharm. 415, 34-52 (2011).

63 Kemme, M., Prokesch, I. \& Heinzel-Wieland, R. Comparative study on the enzymatic degradation of poly(lactic-co-glycolic acid) by hydrolytic enzymes based on the colorimetric quantification of glycolic acid. Polymer Test. 30, 743-748 (2011).

64 Houchin, M. L. \& Topp, E. M. Chemical degradation of peptides and proteins in PLGA: a review of reactions and mechanisms. J. Pharm. Sci. 97, 2395-2404 (2008).

65 Owen, G. R., Jackson, J. K., Chehroudi, B., Brunette, D. M. \& Burt, H. M. An in vitro study of plasticized poly(lactic-co-glycolic acid) films as possible guided tissue regeneration membranes: material properties and drug release kinetics. J. Biomed. Mater. Res. A. 95, 857-869 (2010)

66 Huang, Y. Y., Qi, M., Liu, H. Z., Zhao, H. \& Yang, D. Z. Degradation of porous poly(D,Llactic-co-glycolic acid) films based on water diffusion. J. Biomed. Mater. Res. A. 80A, 909-915 (2007).
67 Wu, X. S. \& Nuo, W. Synthesis, characterization, biodegradation, and drug delivery application of biodegradable lactic/glycolic acid polymers. Part II: Biodegradation. J. Biomater. Sci. Polym. Ed. 12, 21-34 (2001).

68 Faisant, N., Siepmann, J. \& Benoit, J. P. PLGA-based microparticles: elucidation of mechanisms and a new, simple mathematical model quantifying drug release. Eur. $J$. Pharma. Sci. 15, 355-366 (2002).

69 Dunne, M., Corrigan, O. I. \& Ramtoola, Z. Influence of particle size and dissolution conditions on the degradation properties of polylactide-co-glycolide particles. Biomaterials 21, 1659-1668 (2000).

70 Alexis, F., Rath, S. K. \& Venkatraman, S. S. Controlled release from bioerodible polymers: effect of drug type and polymer composition. J. Control. Release 102, 333344 (2005).

(c) (i) (2) (2) This work is licensed under a Creative Commons Attribution-NonCommercial-ShareAlike 3.0 Unported License. To view a copy of this license, visit http://creativecommons. org/licenses/by-nc-sa/3.0/

Supplementary Information accompanies the paper on the NPG Asia Materials website (http://www.nature.com/am) 